\title{
Key factors for adoption of ISO 14001 by the manufacturing industry: a review paper
}

\begin{abstract}
ISO 14001 has been recognised as the world's most popular environmental management system (EMS). Numerous studies have been conducted on EMS adoption factors and benefits. However, the review of coincidences in published findings is conspicuously absent in current research development. The purpose of this study is to examine the degree of coincidence in the adoption factors studied to identify the key elements of ISO 14001 adoption for manufacturing industry. This paper examines the key factors including size of organisation, top management motivation, ISO 9001 experience, perceived benefit, regulatory concern based on the context of resources-based view (RBV), institutional theory, and previous relevant publications. The findings of this research serve as reference for EMS adoption among manufacturing industries. Observation of the relationship between organisation characteristic and EMS implementation could help prepare organisation through its adoption process and enhance the continual improvement of the system.
\end{abstract}

Keyword: ISO 14001; Environmental management system; EMS; Adoption factors; Manufacturing Industries; Size of organisation; Top management motivation; ISO 9001 experience; Perceived benefit; Regulatory concern; Resources-based view; RBV; Resourcesbased view; Institutional theory 